\title{
A high-precision current measurement system for laboratory flume systems: a case study around a circular cylinder
}

\author{
Barbara Springer ${ }^{1, *}$, Michael Friedrichs ${ }^{1}$, Gerhard Graf ${ }^{1}$, \\ Jörg Nittikowski ${ }^{2}$, Wolf́gang Queisser ${ }^{3}$ \\ ${ }^{1}$ University of Rostock, Freiligrathstr. 7/8, D-18055 Rostock, Germany \\ ${ }^{2}$ Am See 15, D-24259 Westensee, Germany \\ ${ }^{3}$ Geomar Research Institute, Wischhoistr. 1-3, D-24148 Kiel, Germany
}

\begin{abstract}
For detailed flow studies around benthic organisms in flumes there is need for a precise velocity sensor that can be positioned accurately. In this paper an automated positioning unit, combined with a velocity sensor, is described for a recirculating salt water flume in which natural sediment cores can be introduced. The spatial resolution of the positioning system is $0.21 \mathrm{~mm}$ in all 3 dimensions. It is equipped with a Sontek acoustic-Doppler velocimeter which has a small sampling volume $\left(0.25 \mathrm{~mm}^{3}\right)$ located $5 \mathrm{~cm}$ below the sensor head. A computer controls both the coupled positioning and sampling procedures. Hence it can follow even complex flow patterns or record the flow regime in a complete $3-D$ grid. Results from flow measurements around a single polychaete tube mimic in the flume show a characteristic vortex pattern with high spatial resolution and reveal the effects on particle fluxes in the benthic boundary-layer. Thus it confirms the findings of previous publications on polychaete tube induced flow patterns and adds new resolution through direct flow measurements around the object.
\end{abstract}

KEY WORDS: Flume Positioning system - Benthic boundary-layer - Flow-pattern A Acoustic-Doppler velocimeter Polychaete tube

Many benthic organisms, directly or indirectly, depend on the interaction with the surrounding flow regime (e.g. Eckman et al. 1981, Carey 1983, Muschenheim 1987, Wildish \& Miyares 1990, Cole et al. 1992, Abelson et al. 1993, Yager et al. 1993, Vogel 1994, Witte et al. 1997). They induce processes like bioresuspension or biodeposition that are relevant for flux calculations in the benthic boundary-layer (Graf \& Rosenberg 1997). The study of small-scale flow dynamics, like those involved in suspension feeding, requires

\footnotetext{
•E-mail: bspringer@geomar.de
}

special attention to the measurement technique, which should be non-intrusive and have high temporal and spatial resolution (e.g. Wildish \& Kristmanson 1997). Among the existing measuring systems, e.g. thermistor probes, electromagnetic current meters, laser-Doppler flow meters or acoustic systems, only a few are suitable for flow measurements on small-scale structures in a flume with appropriate size, accuracy for low flows and without flow interference.

In the present study, a Sontek acoustic-Doppler velocimeter (ADV; Sontek, San Diego, California), combined with a high-precision positioning system, was used in a recirculating flume. It was applied to the flow around a polychaete tube-shaped, circular cylinder. The results were compared with the effects described previously by several authors (e.g. Carey 1983, Eckman \& Nowell 1984, Eckman 1985, Abelson et al. 1993).

Materials and methods. Flume description: The flume channel is $3 \mathrm{~m}$ long and has a width and height of $0.4 \mathrm{~m}$ each. The water level can be up to $25 \mathrm{~cm}$ with a corresponding volume of $420 \mathrm{l}$. The return pipe is located below the main channel (Fig. 1f) and contains a cooling system that allows experiments at controlled temperatures down to $0^{\circ} \mathrm{C}$ (Fig. $1 \mathrm{~g}, \mathrm{~h}$ ). The flow is generated by a propeller (Fig. 1d) located in the return pipe and connected to an adjustable electric motor (Fig, 1e). The maximum free-stream flow velocity is $24 \mathrm{~cm} \mathrm{~s}^{-1}$. Higher velocities can be reached by changing the $\mathrm{V}$-belt pulley of the propeller drive. Honeycombs break up large-scale structures in the flow (Fig. 1c). The test section (Fig. 1a) is located $1.6 \mathrm{~m}$ downstream of the leading edge (honeycomb) and is designed to simulate a wide variety of experimental set-ups, e.g., with artificial model sediment or field 


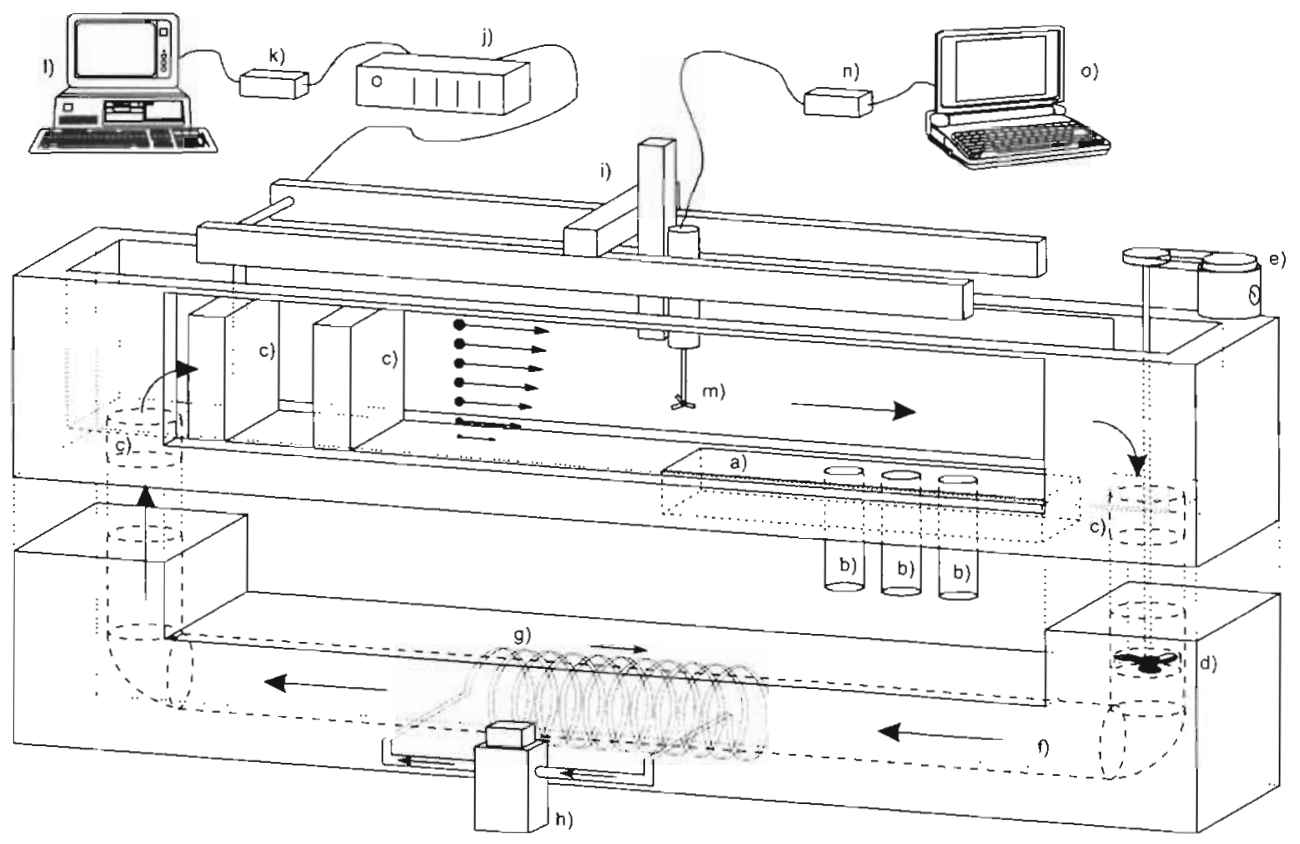

Fig. 1 Schematic drawing of the flume with the moving unit and the ADV sensor. The labels are: (a) test section, (b) sample cores, (c) diffuser grid, (d) propeller, (e) adjustable electric motor, (f) return pipe, (g) cooling coil, (h) cooling unit, (i) positioning rail system, (j) CNCcontroller, (k) adapter (l) positioning $\mathrm{PC},(\mathrm{m})$ acoustic-Doppler velocimeter (ADV), (n) controller, (O) data-recording computer

samples from multiple corers (Barnett et al. 1984). The bottom plate system (Fig. 1a) can be changed and has a length of $105 \mathrm{~cm}$ and a width of $30 \mathrm{~cm}$, kept $5 \mathrm{~cm}$ away of the side walls to avoid boundary effects (Nowell \& Jumars 1987). For experiments with salt water in natural sediments original cores (e.g. from multiple corer) can be introduced from below (Fig. 1b) and adjusted to produce a surface flush with the surrounding sediments (usually the same sediment type without animals). For other experimental set-ups, different types of bottom plates (simple boxes or cores of other diameters) are available.

Flow measurements: All flow measurements were conducted with a Sontek ADV (Fig. 1m), connected to a recording computer and controller (Fig. 1n,o) fixed on the positioning rail system of the flume. Three $10-\mathrm{MHz}$ receiver elements are located in $120^{\circ}$ increments on a circle around a $10-\mathrm{MHz}$ transmitter. They focus on a cylindrical sampling volume of $0.25 \mathrm{~cm}^{3}$ centred in $5 \mathrm{~cm}$ below the sensor head (Fig. 2), which is almost unaffected by flow interference (Kraus et al. 1994). Some acoustic energy is scattered back by small particles in the water. The receiver detects the 'echoes' from the sampling volume that are Doppler shifted, and the 3 orthogonal components of the velocity vector are defined by the interception of the transmit and receive beams. The calibration of the ADV is done in 2 steps. The first step is realised in the factory (determination of exact probe geometry, generating a specific calibration table for each instrument). The resulting coefficients are part of the user-software. The second part is contained in the normal data collection proce- dure. Before each run, the speed of sound is calculated based on site-specific temperature and salinity values that have to be entered in the acquisition program.

Positioning system: The system allows positioning in all 3 directions $(x, y, z)$ to measure the velocity components $u, v$, and $w$ at defined coordinates in the flume. Coordinates can be changed online or predefined as a 1-D, 2-D or 3-D measuring pattern. The system is made of a 3-D mechanical moving unit, driven by stepping motors (Isel-automation, Eiterfeld, Germany) mounted on top of the flume channel (Fig. 1i). Each axis is

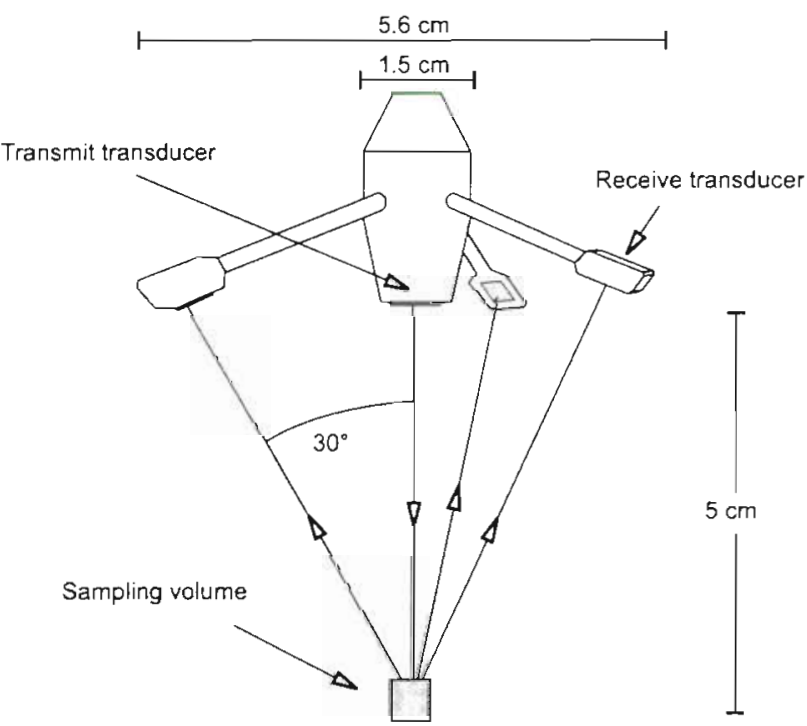

Fig. 2. Operating principle of the Sontek ADV (modified after Kraus et al. 1994) 
equipped with a stepping motor with a spatial resolution of $0.21 \mathrm{~mm}$. The moving unit is operated via a CNCcontroller (Fig, 1j), an adapter (Fig. 1k) and controlled by a PC (Fig. 11). The moving process is started by a computer program (online or trigger mode; for further information about the program and availability contact the authors). The adjustable variables are start and end point of the pattern along each axis, the number and width of the steps between these points, the residence time at each position and the speed of the moving carriage. It is also possible to move a sensor with a defined velocity in each axis through the channel without flow, e.g. to calibrate sensors.

Experimental set-up in the boundary-layer and around a circular cylinder: A comprehensive set of vertical flow speed profiles at 1,5 and $10 \mathrm{~cm} \mathrm{~s}^{-1}$ freestream velocity with a resolution of $2 \mathrm{~mm}$ (sampling time $30 \mathrm{~s}$ for each point) was taken at different locations in the flume to investigate boundary-layer development. A detailed picture of flow dynamics was generated with detailed measurements of the 3 flow components $(u, V, w)$ and their temporal fluctuation (turbulence). Other parameters obtained from the measurement system are the bottom roughness length $z_{0}$, a parameter that gives the height above the bed up to which the flow is influenced by the bottom roughness, and the shear velocity $u$., which gives an estimate of the velocity gradient within the boundary layer and the shear forces on the bed. Both $z_{0}$ and $u$. are derived from the rearranged von-Karman-Prandtl equation (cf. Middleton \& Southard 1984). In addition a Reynolds number based on the flow depth and freestream velocity and the boundary-layer Reynolds number were calculated for each flow condition (Table 1) (cf. Nowell \& Jumars 1987).

A circular PVC cylinder was used to simulate a single polychaete worm tube for the study of the flow dynamics at 3 different flow speeds $\left(1,5\right.$ and $\left.10 \mathrm{~cm} \mathrm{~s}^{-1}\right)$. The cylinder had a diameter of $5 \mathrm{~mm}$ and protruded $35 \mathrm{~mm}$ vertically from the surrounding smooth sediment, which consisted of sieved sand of 100 to $400 \mu \mathrm{m}$ diameter. It was located in the centre of the test section $205 \mathrm{~cm}$ downstream of the leading edge. Flow measurements were taken in a planar 2-D pattern at 0.3 and $2.3 \mathrm{~cm}$ above the sediment, with a horizontal step resolution of $5 \mathrm{~mm}$. Heights were chosen to cover both the effects at bed level, where a direct interaction of flow with the sediment surface occurs, as well as in an intermediate height that should give a generalised picture of the tube-flow interaction. Sampling frequency of all measurements was set to $15 \mathrm{~Hz}$ and the position- ing system remained for $5 \mathrm{~s}$ at each sampling position, recording continuously. Then the relative speed component, as a percent of the mean flow speed at this height in a control measurement without the tube and the turbulence intensity (TI), was calculated from these measurements. TI was determined after Gambi et al. (1990) as a ratio of the vector addition of the fluctuations, expressed as the standard deviation of each flow component, and the vector addition of the mean flow values.

Results. The boundary-layer in the flume: The vertical velocity profiles display a characteristic flow pattern upstream of the cylinder at a free-stream flow of $1 \mathrm{~cm} \mathrm{~s}^{-1}$ (Fig. 3a) on sandy sediment. Bottom boundarylayer thickness was $4 \mathrm{~cm}$ ( $99 \%$ of free-stream velocity [Gust 1989]) with a roughness length $z_{0}$ of $0.04 \mathrm{~cm}$ $(400 \mu \mathrm{m})$ and a shear velocity $u$. of $0.12 \mathrm{~cm} \mathrm{~s}^{-1}$.

At a free-stream flow of $5 \mathrm{~cm} \mathrm{~s}^{-1}$ (Fig. 3b), the boundary-layer thickness was $2.6 \mathrm{~cm}$ with a roughness length of $6 \mu \mathrm{m}$ and a shear velocity of $0.27 \mathrm{~cm} \mathrm{~s}^{-1}$. At $10 \mathrm{~cm} \mathrm{~s}^{-1}$ (Fig. 3c), these were $2.0 \mathrm{~cm}, 1 \mu \mathrm{m}$ and $0.48 \mathrm{~cm}$ $\mathrm{s}^{-1}$, respectively. The mean square error represents the quality of the statistical fit in Fig. 3. Turbulence intensity in the test section reaches $10 \%$ within the boundary-layer.

Flow around an upright circular cylinder: Flow is deflected around a cylinder (Fig. 4) and slowed in a more or less horseshoe-shaped area upstream and along both sides of the cylinder, extending over an area 4 cylinder diameters to each side. Flow speed decreases gradually towards the front of the object. Downstream of the cylinder, a wake zone develops. The $75 \%$-line extends 5 diameters downstream, whereas the area with $<95 \%$ of the upstream flow speed extends 19 diameters downstream in the wake. Along the sides, a slight increase in flow velocity occurs, resulting from the compression of the flow isotachs in this area. The transverse flow component $(v)$ also reveals strong deflection to both sides and a return flow in the wake of the cylinder (Table 2, Fig. 5). The vertical component $(w)$ displays a strong downward movement in front of the cylinder, followed by upwelling along the downstream face of the cylinder (Table 2, Fig. 5b). 

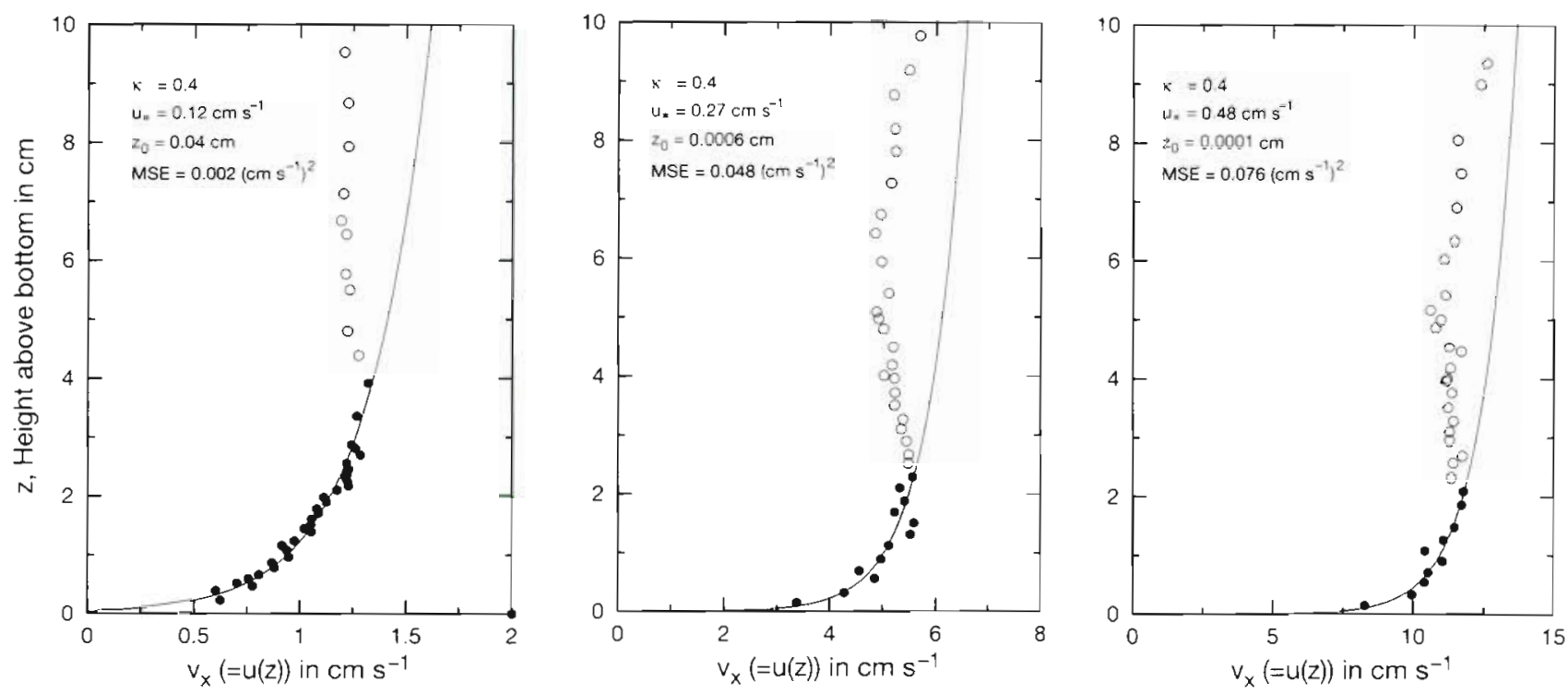

Fig. 3. Vertical profiles of $u$ at 1 (a), 5 (b) and $10 \mathrm{~cm} \mathrm{~s}^{-1}$ (c) free stream velocity in the test section. Sampling frequency was $15 \mathrm{~Hz}$ and averaging time $30 \mathrm{~s}$. The line displays the fit function (calculated from the filled dots) (MSE: mean square error)

Turbulence intensity behind the cylinder increases with flow speed and shows a turbulent zone in the wake area downstream of the cylinder. The $20 \%$ turbulence intensity level extends 5,8 and 14 cylinder diameters downstream at 1,5 and $10 \mathrm{~cm} \mathrm{~s}^{-1}$, respectively, and thus gives an idea of the area affected by the tube.

Discussion. Vertical velocity profiles show the boundary layer development expected from the vonKarman-Prandtl equation. It is possible to simulate laminar and smooth turbulent flow in the flume used here, as demonstrated for example by the boundarylayer Reynolds numbers, ranging between 500 and 2000. A critical number separating laminar and fully turbulent boundary-layer flow conditions is 3000 (Nowell \& Jumars 1987). Monismith et al. (1990) state that a similarity of both $u$. and $z_{0}$ with field conditions is sufficient to represent a natural, near-bed flow regime in flume experiments. Gust (1989) gives typical $u$. field values of 0.04 to $0.8 \mathrm{~cm} \mathrm{~s}^{-1}$ for the deep sea and 0.4 to $2 \mathrm{~cm} \mathrm{~s}^{-1}$ for the shelf with corresponding $z_{0}$ values ranging from $0.1 \mathrm{~cm}$ (deep sea) to $5 \mathrm{~cm}$ (shelf).

Nowell \& Jumars (1987) consider flumes designed according to Vogel (1994) are unsuited for boundarylayer work because of size, 3-D flow (impact of the side walls) and entrance conditions. The flume described here is similar to that designed by Vogel; to avoid the above-mentioned problems the flume was built in a different size and with different entrance conditions. The measuring system described here did not detect 3-D flow in the test section. Hence, the objects placed in the test section encounter flow conditions close to

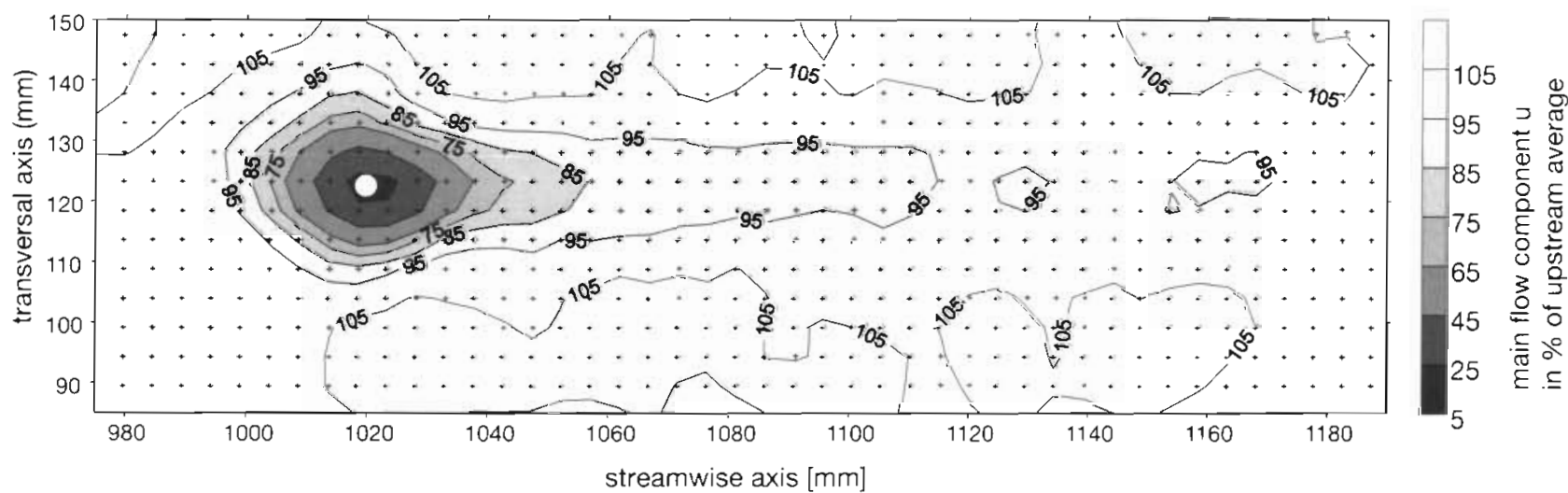

Fig. 4. Flow pattern around a single upright cylinder of $3.5 \mathrm{~cm}$ height, measured in a height of $2.3 \mathrm{~cm}$ above the sediment with a grid resolution of $5 \mathrm{~mm}$ steps (measured positions indicated as crosses, sampling frequency $15 \mathrm{~Hz}$ and averaging time 5 s).

The isolines show the relative horizontal flow (in \%) of the upstream mean flow speed (free-stream flow: $1 \mathrm{~cm} \mathrm{~s}^{-1}$ ) 
Table 2. Summary of the flow deflection by an upright cylinder, measured at different heights above the sediment. Freestream velocity was $5 \mathrm{~cm} \mathrm{~s}^{-1}$ Vertical flow is given in negative values when moving downward and positive values when directed away from the bed. Transverse flow faced away from the object on the upstream side and back downstream of it. The values given here are maximum values obtained in the centre of the respective flow field (cf. Fig. 5)

\begin{tabular}{|lcccc|}
\hline $\begin{array}{l}\text { Height } \\
\text { above bed } \\
(\mathrm{cm})\end{array}$ & \multicolumn{2}{c}{$\begin{array}{c}\text { Transverse flow } \\
\text { component } \\
\left(v \text { in } \mathrm{cm} \mathrm{s}^{-1}\right)\end{array}$} & \multicolumn{2}{c|}{$\begin{array}{c}\text { Vertical flow } \\
\text { component } \\
\left(w \text { in } \mathrm{cm} \mathrm{s}^{-1}\right)\end{array}$} \\
$\begin{array}{l}\text { Upstream } \\
\text { of cylinder }\end{array}$ & $\begin{array}{l}\text { Down- } \\
\text { stream }\end{array}$ & Upstream & $\begin{array}{c}\text { Down- } \\
\text { stream }\end{array}$ \\
\hline 3.3 & 0.1 & 0.1 & +0.3 & -0.1 \\
1.3 & 0.5 & 0.5 & -0.1 & +0.4 \\
0.3 & 0.6 & 0.8 & -0.5 & +0.5 \\
\hline
\end{tabular}

those usually found in shallow-water environments. The flow regime around a cylinder protruding into a bottom boundary-layer is summarised and generalised in the following: a solid cylindrical object like a polychaete tube deflects the main flow laterally, while only a small portion is deflected vertically. This part is deflected mainly downwards along the cylinder body and generates a vortex at its base (e.g. Carey 1983). This vortex surrounds the object within a horseshoeshaped area. Along the back of the object, the water from this vortex exhibits a strong upward movement that mixes with the turbulent rotational pattern created at the tip of the cylinder and results in a highly turbulent wake area with a low net horizontal flow speed.

Particles trapped in this wake area have a long residence time and are likely to settle on the bed (Carey 1983). Conversely, the strong vortex around the base of the cylinder generates erosion. These assumptions were confirmed by direct observation of sediment movement around the object. A pit is created on the front and sides of the cylinder, and a mound builds up in the wake area. These findings confirm previous observations described by different authors (e.g. Eckman \& Nowell 1984). Carey (1983) described similar flow conditions, observed by tracking the path of egg albumine particles around polychaete tubes of Lanice conchilega. In that study, the upward transport of particles away from the bed was found-in the wake of the tubes it increased by a factor of 2 . The present measurements and our previous studies with tracers (dye) and video observation show pathlines similar to those given by Eckman \& Nowell (1984), obtained from measurements of skin friction around a polychaete tube-mimic (Fig. 6).
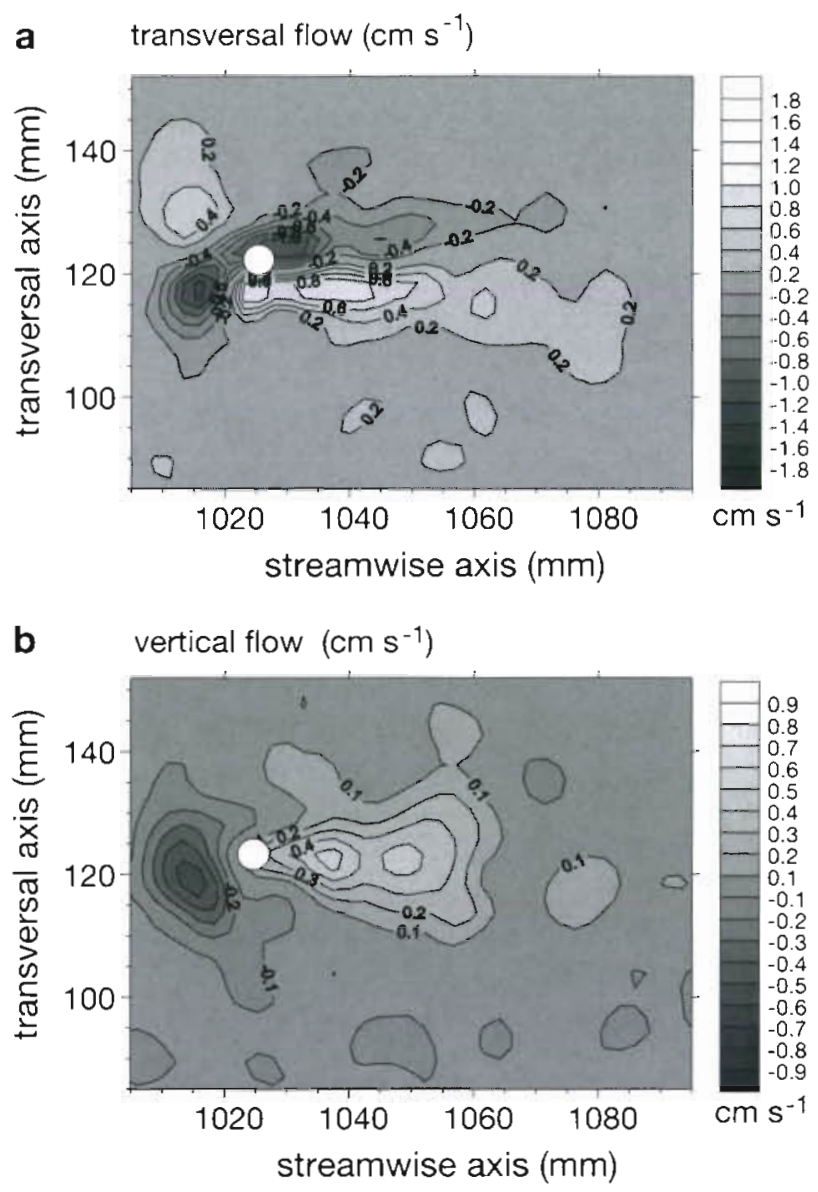

Fig. 5. Flow pattern around a circular cylinder, measured at $0.3 \mathrm{~cm}$ above the sediment with a free-stream flow of $1 \mathrm{~cm} \mathrm{~s}^{-1}$ : (a) transversal flow speeds (in $\mathrm{cm} \mathrm{s}^{-1}$ ); (b) the vertical flow component (in $\mathrm{cm} \mathrm{s}^{-1}$ )
Fig. 6. Flow pathlines around a circular cylinder resulting from the measured data (modified after Eckman \& Nowell 1984)

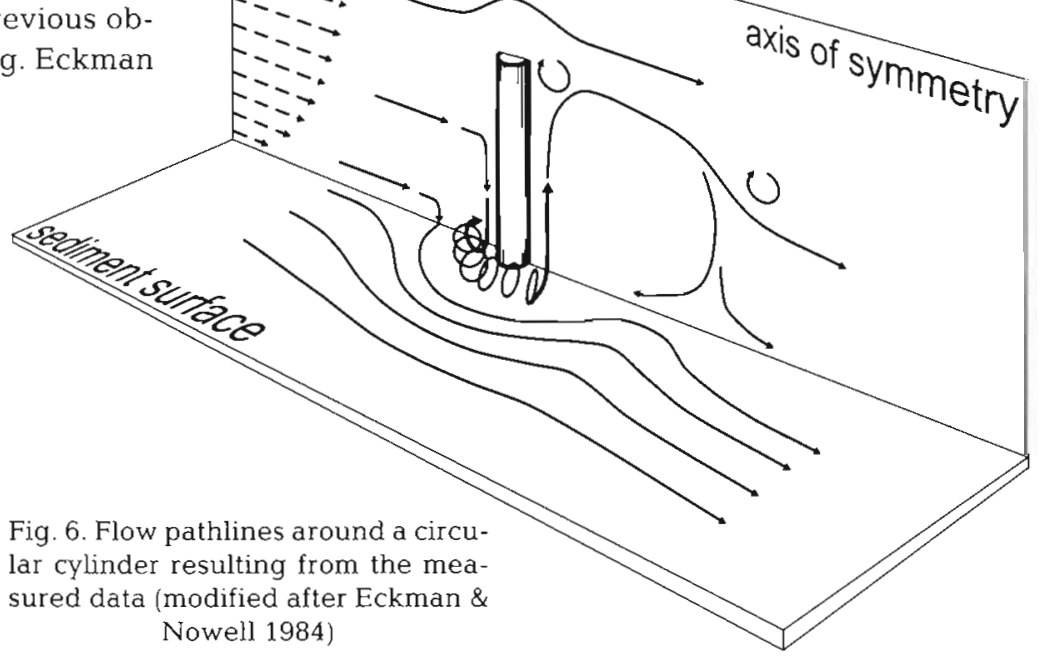


In conclusion, the described system of an acoustic flow sensor with small sampling volume combined with a high spatial-resolution positioning system allows a detailed, 3-D picture of the flow dynamics, even in the surroundings of small organisms under natural conditions. A restriction of the sampling method is the fact that it is a single-point measurement device. It can either give local fluctuations with high temporal resolution (up to $25 \mathrm{~Hz}$ sampling rate; a new generation reaches even $100 \mathrm{~Hz}$ ) or a 2-D/3-D-overview of averaged flow effects. The resulting data set is not truly synoptic and therefore gives an incomplete picture of instantaneous turbulent fluctuations. Distribution of turbulent intensity of 10 to $12 \%$ in our flume without biogenic structures is similar to field conditions (Middleton \& Southard 1984). An overview of measurements of turbulent parameters and spectral analysis of ADV in the laboratory and in the field was published in VouIgaris \& Trowbridge (1998). Nevertheless, a stationary vortex trail was observed downstream of the cylinder in 1 experiment. The acoustic sensor permits measurements in the vicinity of objects and even between them (such as within a polychaete tube lawn) without interfering with these objects. In general, highly mobile objects and complex, unstable flow fields cannot be recorded properly with the presented method. It is however a good tool for assessment of trends and steady flow patterns on a small scale or for point measurement of turbulent fluctuations in the surroundings of macrobenthic organisms. It thus enables better understanding of flow-sediment-organism interactions and related food-particle dynamics in benthic environments.

Acknowledgements. The development, construction, testing and use of the flume with the high spatial-resolution measuring system was supported by the German Federal Department of Education and Research (BMBF), FKZ \# 03F0065. Helpful comments were provided by 4 anonymous reviewers.

\section{LITERATURE CITED}

Abelson A, Miloh T, Loya Y (1993) Flow patterns induced by substrata and body morphologies of benthic organisms, and their roles in determining availability of food particles. Limnol Oceanogr 38:1.116-1124

Barnett PRO, Watson J, Conelly D (1984) A multiple corer for taking virtually undisturbed samples from shelf, bathyal and abyssal sediments. Oceanol Acta 7:339-409

Editorial responsibility: Otto Kínne (Editor),

Oldendorf/Luhe, .Germany
Carey DA (1983) Particle resuspension in the benthic boundary layer induced by flow around polychaete tubes. Can J Fish Aquat Sci 40 (Suppl 1):301-308

Cole BE, Thompson JK, Cloern JE (1992) Measurement of filtration rates by infaunal bivalves in a recirculdting flume. Mar Biol 113:219-225

Eckman JE (1985) Flow disruption by an animal-tube mimic affects sediment bacterial colonization. J Mar Res 43: $419-435$

Eckman JE, Nowell ARM (1984) Boundary skin friction and sediment transport about an animal-tube mimic. Sedimentology 31:851-862

Eckman JE, Nowell AR, Jumars PA (1981) Sediment destabilisation by animal tubes. J Mar Res 39:361-374

Gambi MC, Nowell ARM, Jumars PA (1990) Flume observations on flow dynamics in Zostera marina (eelgrass) beds Mar Ecol Prog Ser 61:159-169

Graf G, Rosenberg R (1.997) Bioresuspension and biodeposition: a review. J Mar Syst 11:269-278

Gust G (1989) The benthic boundary layer. In: Hellwege $\mathrm{KH}_{1}$ Madelung $O$ (eds) Landolt Börnstein, numerical data and functional relationships, Vol 3b. Oceanography. Springer Verlag, Berlin p 345-398

Kraus NC, Lohrman A, Cabrera R (1994) New acoustic meter for measuring 3D laboratory flows. J Hydraulic Eng 120: $406-412$

Middleton GV, Southard JB (1984) Mechanics of sediment movement, short course No. 3. Society of Sedimentary Geologists (SEPM), Providence

Monismith SG, Koseff JR, Thompson JK, O'Riordan CA, Nepf HM (1990) A study of model bivalve siphonal currents. Limnol Oceanogr 35 (3):680-696

Muschenheim DK (1987) The role of hydrodynamic sorting of seston in the nutrition of a benthic suspension feeder, Spia setosa (Polychaeta: Spionidae). Biol Oceanogr (NY) 4(3): $265-288$

Nowell ARM, Jumars PA (1987) Flumes: theoretical and experimental consideration for simulation of benthic environments. Oceanogr Mar Biol Annu Rev 25:91-112

Vogel S (1994) Life in moving fluids. The physical biology of flow, 2nd edn. Princeton University Press, Princeton

Voulgaris G. Trowbridge $\mathrm{JH}$ (1998) Evaluation of the acoustic Doppler velocimeter (ADV) for turbulence measurements. J Atmos Ocean Technol 15(1):272-289

Wildish D, Kristmanson D (1997) Benthic suspension feeders and flow. Cambridge University Press, Cambridge

Wildish DJ, Miyares MP (1990) Filtration rate of blue mussels as function of flow velocity: preliminary results. J Exp Mar Biol Ecol 142:213-219

Witte U, Brattegard T, Graf G, Springer B (1997) Particle capture and deposition by deep-sea sponges from the Norwegian-Greenland Sea. Mar Ecol Prog Ser 154:241-252

Yager PL, Nowell ARM, Jumars PA (1993) Enhanced deposition to pits: a local food source for benthos. J Mar Res 51: $209-236$

Submitted: November 24, 1998; Accepted: February 15, 1999 Proofs received from author(s): June 28, 1999 